\title{
Statistical Optimization of the Medium Composition by Response Surface Methodology to Enhance Schizophyllan Production by Schizophyllum commune
}

\author{
Wenbing $\mathrm{Li}^{\mathrm{a}, \S}$, Pengpeng $\mathrm{Zhou}^{\mathrm{b}, \S}$, and Longjiang $\mathrm{Yu}^{\mathrm{b}, *}$ \\ a College of Chemical Engineering and Technology, Wuhan University of Science \\ and Technology, Wuhan, 430081, P. R. China \\ b College of Life Science and Technology, Huazhong University of Science \\ and Technology, Wuhan, 430074, P. R. China. Fax: +86-27-8779-2265. \\ E-mail: liwenbing@126.com or yulongjiang@mail.hust.edu.cn \\ * Author for correspondence and reprint requests \\ Z. Naturforsch. 66 c, 173-181 (2011); received March 20/October 5, 2010
}

The response surface methodology (RSM) involving central composite design (CCD) was employed to optimize the fermentation medium for the cell growth and schizophllan production by Schizophyllum commune CGMCC 5.113 in submerged culture at pH 6.5 and $26{ }^{\circ} \mathrm{C}$. The four variables involved in this study were glucose, yeast extract, ammonium nitrate, and magnesium sulfate. The statistical analysis of the results showed that, in the range studied, glucose and yeast extract had a highly significant effect on schizophyllan production. The optimal medium for schizophyllan production calculated from the regression model of RSM was as follows: glucose, $18 \mathrm{~g} / \mathrm{l}$; yeast extract, $0.5 \mathrm{~g} / \mathrm{l} ; \mathrm{NH}_{4} \mathrm{NO}_{3}, 0.48 \mathrm{~g} / \mathrm{l}$; and $\mathrm{MgSO}_{4}, 0.05 \mathrm{~g} / \mathrm{l}$, with a predicted maximum schizophyllan production of $11.74 \mathrm{~g} / \mathrm{l}$. These predicted values were experimentally validated. The excellent correlation between predicted and measured values justifies the validity of the response model. The results of bioreactor fermentation also show that the optimized medium enhanced schizophyllan production $(12.80 \mathrm{~g} / \mathrm{l})$ by $S$. commune in a 5-1 fermenter.

Key words: Schizophyllan, Response Surface Methodology, Medium Optimization

\section{Introduction}

Schizophyllum commune is a species of the basidiomycetes which belongs to the order Agaricales and the family Schizophyllaceae (Bolla et al., 2008; Hao et al., 2010). It is a very common fungus and has a world-wide distribution (Hobbs, 1995). In particular, this fungus has been regarded as a popular healthy food and an effective medicine used in the therapy of some diseases in the Orient for centuries. Pharmacologically it is extremely important because it produces the polysaccharide schizophyllan (Rau, 1999), a homoglucan consisting of a linear chain of $\beta$-D- $(1 \rightarrow 3)$-glucopyranosyl groups and $\beta$-D-( $1 \rightarrow 6)$-glucopyranosyl groups, produced by fermentation of filamentous S. commune (Rau, 2002). This polysaccharide has attracted much attention by pharmaceutical industry in recent years because its immunomodulatory, antineoplastic and antiviral activities are higher than those of other glucans (Kumari et al., 2008; Tabata

\footnotetext{
$\S$ These authors contributed equally to this work.
}

et al., 1981). Furthermore, schizophyllan has been applied in enhanced mineral oil recovery (Leathers et al., 2006; Wagner, 1988), in cosmetics (Rau and Brandt, 1994), and food preservation (Hao et al., 2010; Leathers et al., 2006). Currently, schizophyllan is commercially produced in Japan as an antitumour agent with the trade name Sizofiran (Leathers et al., 2006). Although its structure and its applications have been well documented in the literature in the last decade, relatively little research has focused on factors affecting the production of schizophyllan. To achieve higher yields in submerged culture, it is a prerequisite to design an optimal production medium.

The optimization of a fermentation medium is an important step in the development of economically feasible bioprocesses. The successful design of a fermentation process involves optimizing the media composition, fermentation conditions, and fermenter design as well as developing superior strains by mutation (Margaritis and Pace, 1985). Medium optimization by employing the one-fac- 
tor-at-a-time method involves changing one independent variable while fixing all the others at a certain level. This single-dimensional approach is laborious and time-consuming, especially for a large number of variables, and frequently does not guarantee the determination of optimal conditions (Luo et al., 2009; Survase et al., 2006). Such drawback of the one-factor-at-a-time method can be overcome by statistical optimization techniques (Chen et al., 2008). Factorial design and response surface methodology (RSM) are important statistical optimization methods for the optimization of many variables by only a few experimental trials (Malinowska et al., 2009).

RSM is a collection of statistical techniques for designing experiments, building models, evaluating the effects of factors, and searching for the optimum conditions. RSM has been successfully used in the optimization of bioprocesses where the target production could be enhanced, especially in the cultivation process of many edible and medicinal mushrooms (Hao et al., 2010; Kalil et al., 2000; Kumari et al., 2008; Luo et al., 2009). However, there is still lack of knowledge concerning the optimization of the medium for schizophyllan production by Schizophyllum commune in submerged culture by statistical techniques.

The aim of the present study was to establish the optimal medium for the production of schizophyllan by Schizophyllum commune using RSM. In the first step, the one-factor-at-a-time method was used to investigate the effect of media components. Subsequently, an optimal medium composition was attained by full $2^{4}$ factorial plus 7 centre points central composite design (CCD) using RSM. Finally, with the optimal medium, the cell growth (biomass) and schizophyllan production were investigated in a 5-1 fermenter.

\section{Material and Methods}

\section{Microorganism}

Schizophyllum commune (CGMCC 5.113) used in this study was kindly provided by the China General Microbiological Culture Collection of the Chinese Academy of Sciences. The stock culture was maintained on a potato dextrose agar (PDA) slant containing (per liter): $200 \mathrm{~g}$ potato juice, $20 \mathrm{~g}$ glucose, $0.5 \mathrm{~g} \mathrm{MgSO}_{4} \cdot 7 \quad \mathrm{H}_{2} \mathrm{O}, 3.0 \mathrm{~g}$ $\mathrm{KH}_{2} \mathrm{PO}_{4}$, and $20 \mathrm{~g}$ agar, and subcultured once a month. The slants were incubated at $25^{\circ} \mathrm{C}$ for $7 \mathrm{~d}$, and then stored at $4{ }^{\circ} \mathrm{C}$.

\section{Flask culture}

The culture medium selected for studies on schizophyllan production comprised the following (per liter): $12 \mathrm{~g}$ glucose, $1 \mathrm{~g}$ yeast extract, $0.2 \mathrm{~g} \mathrm{KH}_{2} \mathrm{PO}_{4}, 0.1 \mathrm{~g} \mathrm{MgSO}_{4} \cdot 7 \mathrm{H}_{2} \mathrm{O}, \mathrm{pH}$ 6.5. The $\mathrm{pH}$ value of the medium was initially adjusted to 6.5 , followed by its autoclaving at $121{ }^{\circ} \mathrm{C}$ for $20 \mathrm{~min}$. The seed culture obtained by transferring approximately $1.0 \mathrm{~cm}^{2}$ of slant culture into a 250 $\mathrm{ml}$ Erlenmeyer flask containing $100 \mathrm{ml}$ seed medium was grown at $28{ }^{\circ} \mathrm{C}$ on a rotary shaker at $150 \mathrm{rpm}$ for $5 \mathrm{~d}$.

The flask culture experiments were performed in 250-ml flasks, containing $100 \mathrm{ml}$ of the above medium. After inoculating with $10 \%(\mathrm{v} / \mathrm{v})$ of seed culture, the culture was incubated at $26{ }^{\circ} \mathrm{C}$ in a rotary shaker incubator at $180 \mathrm{rpm}$ for $7 \mathrm{~d}$.

\section{Bioreactor fermentation}

The bioreactor fermentation was carried out in a 5-1 fermenter (BIOSTAT B plus, B. Braun Biotech International, Melsungen, Germany) with a working volume of 31 and $10 \%$ inoculation volume $(\mathrm{v} / \mathrm{v})$ at $26{ }^{\circ} \mathrm{C}$ for $7 \mathrm{~d}$. The composition of the medium was optimal for schizophyllan production calculated from the result of RSM. The agitation rate remained at $180 \mathrm{rpm}$. The culture was aerated at a rate of $1 \mathrm{vvm}$ and the $\mathrm{pH}$ value was controlled using $1 \mathrm{~m} \mathrm{NaOH}$ and $1 \mathrm{~m} \mathrm{HCl}$.

\section{Optimization of fermentation medium using the one-factor-at-a-time method}

The effects of carbon source, nitrogen sources, and the initial $\mathrm{pH}$ value on schizophyllan production were examined by the one-factor-at-a-time method. Glucose was substituted with six different carbon sources viz., sucrose, maltose, fructose, lactose, soluble starch, and corn starch. Initially, all carbon sources were screened at $12 \mathrm{~g} / \mathrm{l}$. Yeast extract was replaced with other organic nitrogen sources such as peptone, acid-hydrolyzed casein, and inorganic nitrogen sources like sodium nitrate, ammonium nitrate, and urea at the nitrogen concentration of $1 \mathrm{~g} / \mathrm{l}$. The medium was adjusted to different $\mathrm{pH}$ levels varying from 5.0 to 8.0 with $1 \mathrm{~m} \mathrm{NaOH}$ and $1 \mathrm{~m} \mathrm{HCl}$. Fermentation was carried out at $26^{\circ} \mathrm{C}$ and $180 \mathrm{rpm}$ for $7 \mathrm{~d}$.

\section{Optimization of medium components by RSM}

RSM is a statistical modeling technique used for multiple regression analysis of quantitative 
data obtained from rationally designed experiments to solve multivariable equations simultaneously (Kumari et al., 2008; Rao et al., 2000). The ingredients concentrations of medium for the production of schizophyllan were optimized by RSM. The experiments were designed with CCD using the software Design Expert Version 7.0.0 trial version (State Ease, Minneapolis, MN, USA). The culture medium components (independent variables) selected for optimization were carbon source, nitrogen source, and mineral elements. Regression analysis was performed on the data obtained from the design experiments. The following equation was used to code the test variables:

$$
X_{i}=\frac{x_{i}-x_{i}^{0}}{\Delta x_{i}}, i=1,2,3, \cdots, k
$$

where $X_{i}$ is the dimensionless coded value of the $i$-th test variable, $x_{i}$ is the real value of the $i$-th test variable, $x_{i}^{0}$ is the real value of the $i$-th test variable at the centre point, and $\Delta x_{i}$ is the step change value.

The relationship between the independent variables (nutrient medium components) and the response (schizophyllan production) was fitted to a predictive second-order polynomial equation:

$Y=\beta_{0}+\sum_{i=1}^{k} \beta_{i} X_{i}+\sum_{i=1}^{k} \beta_{i i} X_{i}^{2}+\sum_{i<1}^{k} \sum \beta_{i j} X_{i} X_{j}$

where $Y$ is the predicted response, subscripts $i$ and $j$ assume values from 1 to the number of variables, $\beta_{0}$ is a constant, $\beta_{i}$ is the linear coefficient, $\beta_{i i}$ is the quadratic coefficient, $\beta_{i j}$ is the cross-product coefficient, $k$ is the number of factors, and $X_{i}$ and $X_{j}$ are the coded dimensionless values of the investigated variables. The software mentioned above was used for the experimental design, the analysis of variance (ANOVA), and the graphical analysis of the data. The statistical significance of the quadratic model was assessed using the $F$-test, and the quality of fit was evaluated by the coefficient of determination $R^{2}$. The significances of the regression coefficients were tested by a $t$-test, and the $p$ values were used as a tool to check the significance of each coefficient.

\section{Determination of fungal biomass and schizophyllan production}

A flask containing $50 \mathrm{ml}$ fermentation broth was taken from the shaker. Broth $(10 \mathrm{ml})$ from the flask was filtered to separate fungal biomass, which was washed three times with distilled water and dried at $65^{\circ} \mathrm{C}$ to constant weight; it was reported as dry cell weight (DCW). The supernatant was used for estimation of schizophyllan dry weight (Hsieh et al., 2005). Two volumes of absolute ethanol were added to precipitate the polysaccharide from the clear supernatant. The mixture was allowed to stand for $12 \mathrm{~h}$ at $4{ }^{\circ} \mathrm{C}$ for complete precipitation. The precipitated polysaccharide was collected by centrifugation at $6,000 \times g$ for $15 \mathrm{~min}$, then dried at $65^{\circ} \mathrm{C}$ to remove the residual ethanol, and quantified as dry weight (Maziero et al., 1999).

\section{Results and Discussion}

\section{Effect of carbon}

During microbial culture, the carbon source functions as a source of both energy and constituent cellular material (Kumari et al., 2008). Fig. 1 shows the effect of different carbon sources on schizophyllan and biomass production by $S$. commune. Glucose and sucrose supported the mycelial growth best. Glucose allowed the highest production of $11.20 \mathrm{~g} / \mathrm{l}$ schizophyllan, whereas sucrose gave a yield of $10.20 \mathrm{~g} / \mathrm{l}$ schizophyllan after $7 \mathrm{~d}$ of cultivation. Likewise, glucose provided maximal biomass (measured as DCW), while corn starch was least effective. Glucose has also been identified as being ideally suited for exopolysaccharide (EPS) production in fungi such as Agaricus brasiliensis (Shu and Xu, 2007), Grifola fron-

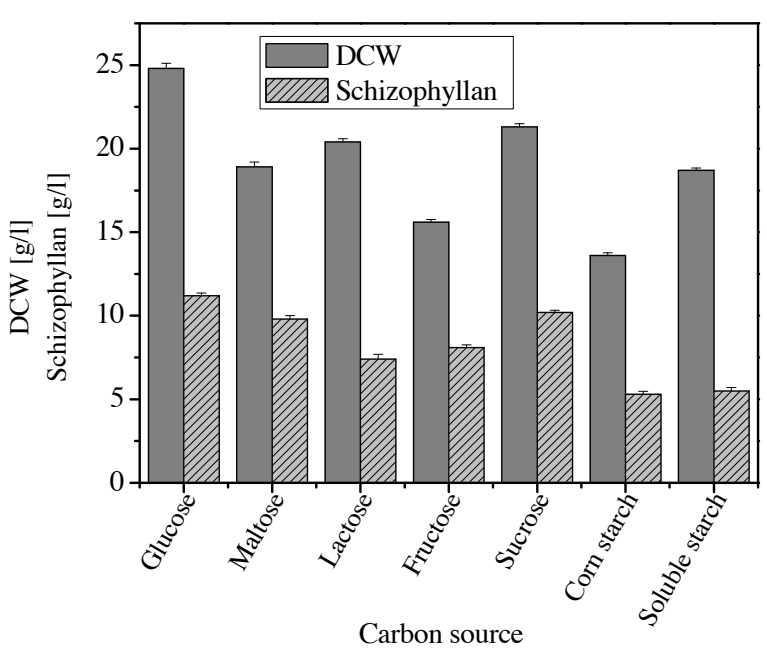

Fig. 1. Effect of different carbon sources on schizophyllan and biomass production (DCW) by $S$. commune. (Carbon source, $12 \mathrm{~g} / \mathrm{l}$; yeast extract, $1 \mathrm{~g} / \mathrm{l}$.) 


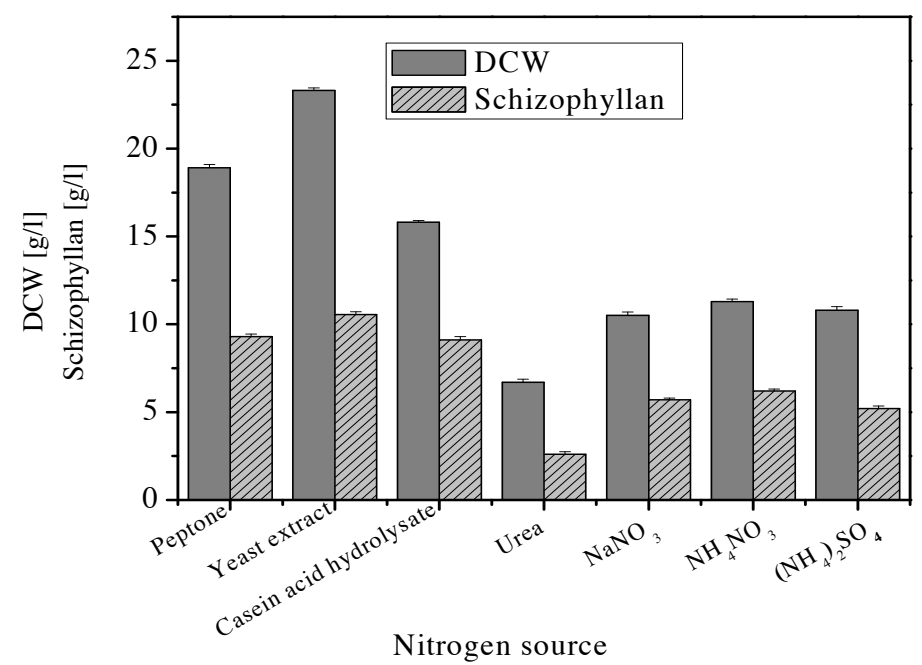

Fig. 2. Effect of different nitrogen sources on schizophyllan and biomass production (DCW) by S. commune. (Nitrogen concentration, $1 \mathrm{~g} / \mathrm{l}$; glucose, $12 \mathrm{~g} / \mathrm{l}$.)

dosa (Lee et al., 2004), and Pleurotus pulmonarius (Nour El-Dein et al., 2004).

\section{Effect of the nitrogen source}

Fig. 2 shows the effect of different organic and inorganic nitrogen sources $(1 \mathrm{~g} / \mathrm{l}$, calculated as nitrogen) on schizophyllan and biomass production by $S$. commune. Nitrogen is a critical factor in the synthesis of some fungal enzymes involved in both primary and secondary metabolism (Malinowska et al., 2009). Limiting nitrogen in the medium can result in considerable inhibition of cell growth and metabolite production (Kim et al., 2005). This nutrient element can be supplied to the culture medium in the form of ammonium or nitrate ions, or in organic form (such as free amino acids or proteins).

Among the three selected organic nitrogen sources (yeast extract, peptone, and acid-hydrolyzed casein), yeast extract gave the highest yield of $10.56 \mathrm{~g} / \mathrm{l}$ schizophyllan. Among the four inorganic nitrogen sources, ammonium nitrate provided the highest yield of $6.2 \mathrm{~g} / 1$ schizophyllan. Considerably lower fungal growth was observed in culture medium containing urea as nitrogen source. Ammonium nitrate, an inexpensive nitrogen source, gave better results and was used in the subsequent experiments.

\section{Effect of the initial $\mathrm{pH}$}

The effect of different initial $\mathrm{pH}$ values on schizophyllan and biomass production was stud- ied. As shown in Table I, an initial $\mathrm{pH}$ of 6.5 supported the highest production of $10.84 \mathrm{~g} / 1$ schizophyllan, whereas maximum biomass production was obtained at $\mathrm{pH}$ 7.0. Kumari et al. (2008) observed a similar relationship with $S$. commune NRCM. The one-way ANOVA for different initial $\mathrm{pH}$ values experiments shows that initial $\mathrm{pH}$ values exhibit an excellent correlation with biomass and schizophyllan productions, with high $F$ values (31.93 and 6.20 for biomass and schizophyllan production, respectively) and $p<0.05$. The initial $\mathrm{pH}$ value of the medium has significant effects on biomass growth and schizophyllan production. As different authors have reported different optimal $\mathrm{pH}$ values for EPS production, it seems that changes in this environmental factor lead to certain changes in the EPS yield that

Table I. Effect of initial $\mathrm{pH}$ value on biomass and schizophyllan production in flask culture of S. commune.

\begin{tabular}{llc}
\hline $\mathrm{pH}$ & Biomass $[\mathrm{g} / \mathrm{l}]$ & Schizophyllan $[\mathrm{g} / \mathrm{l}]$ \\
\hline 5.0 & $18.96 \pm 0.82$ & $9.03 \pm 1.4$ \\
5.5 & $20.08 \pm 0.42$ & $8.74 \pm 0.9$ \\
6.0 & $21.38 \pm 0.53$ & $9.86 \pm 1.6$ \\
6.5 & $21.48 \pm 0.36$ & $10.84 \pm 0.68$ \\
7.0 & $21.89 \pm 0.9$ & $8.76 \pm 1.1$ \\
7.5 & $19.82 \pm 0.8$ & $6.64 \pm 1.0$ \\
8.0 & $15.32 \pm 0.78$ & $5.86 \pm 1.5$ \\
\hline
\end{tabular}

All experimental data shown here are the mean \pm SD of triplicate determinations. Means are significantly different according to one-way ANOVA at $p<0.05$. 
Table II. The coded and real values of variables of medium composition.

\begin{tabular}{lrrrrr}
\hline \multirow{2}{*}{ Independent } & \multicolumn{5}{c}{ Variable levels } \\
\cline { 2 - 6 } & \multicolumn{1}{c}{-2} & \multicolumn{1}{c}{-1} & \multicolumn{1}{c}{0} & \multicolumn{1}{c}{1} & \multicolumn{1}{c}{2} \\
\hline$X_{1}$, glucose $(\mathrm{g} / \mathrm{l})$ & 10.0 & 12.0 & 14.0 & 16.0 & 18.0 \\
$X_{2}$, yeast extract $(\mathrm{g} / \mathrm{l})$ & 0.5 & 0.6 & 0.7 & 0.8 & 0.9 \\
$X_{3}, \mathrm{NH}_{4} \mathrm{NO}_{3}(\mathrm{~g} / \mathrm{l})$ & 0.1 & 0.20 & 0.30 & 0.40 & 0.5 \\
$X_{4}, \mathrm{MgSO}_{4}(\mathrm{~g} / \mathrm{l})$ & 0.05 & 0.10 & 0.15 & 0.20 & 0.25 \\
\hline
\end{tabular}

vary depending on the mushroom species, which indicates that there are differences in the environmental requirements of various mushroom strains (Cho et al., 2006; Huang et al., 2007; Kim et al., 2005; Malinowska et al., 2009 ).

\section{Optimizing the medium composition by RSM}

The experiments performed by RSM are based on mathematical techniques that allow us to investigate the relationships between variables of medium components. This method has been successfully applied in the optimization of medium compositions and fermentation processes. Based on the results obtained from the one-factorat-a-time experiments, four factors exerted the greatest effects on cell growth and schizophyllan production. Four medium components at four different levels were selected for optimization. These were: carbon source, two nitrogen sources, and mineral elements (such as $\mathrm{MgSO}_{4}$ ). The $\mathrm{pH}$ value of the culture medium was 6.5 , which was

Table III. Central composite rotatable design (CCD) matrix of independent variables and the corresponding experimental results (the response).

\begin{tabular}{|c|c|c|c|c|c|c|}
\hline \multirow{2}{*}{$\begin{array}{l}\text { Treatment } \\
\text { no. }\end{array}$} & \multicolumn{4}{|c|}{ Medium components $[\mathrm{g} / \mathrm{l}]$} & \multicolumn{2}{|c|}{ Schizophyllan $[\mathrm{g} / \mathrm{l}]$} \\
\hline & Glucose & Yeast extract & $\mathrm{NH}_{4} \mathrm{NO}_{3}$ & $\mathrm{MgSO}_{4}$ & Predicted & Experimental \\
\hline 1 & -1 & -1 & -1 & -1 & 6.25 & 5.20 \\
\hline 2 & 1 & -1 & -1 & -1 & 11.69 & 12.00 \\
\hline 3 & -1 & 1 & -1 & -1 & 5.48 & 4.80 \\
\hline 4 & 1 & 1 & -1 & -1 & 6.57 & 6.87 \\
\hline 5 & -1 & -1 & 1 & -1 & 5.75 & 5.00 \\
\hline 6 & 1 & -1 & 1 & -1 & 12.25 & 12.40 \\
\hline 7 & -1 & 1 & 1 & -1 & 6.13 & 5.20 \\
\hline 8 & 1 & 1 & 1 & -1 & 8.29 & 8.80 \\
\hline 9 & -1 & -1 & -1 & 1 & 7.42 & 6.40 \\
\hline 10 & 1 & -1 & -1 & 1 & 11.52 & 11.95 \\
\hline 11 & -1 & 1 & -1 & 1 & 5.61 & 4.96 \\
\hline 12 & 1 & 1 & -1 & 1 & 5.37 & 5.60 \\
\hline 13 & -1 & -1 & 1 & 1 & 6.47 & 5.68 \\
\hline 14 & 1 & -1 & 1 & 1 & 11.64 & 11.80 \\
\hline 15 & -1 & 1 & 1 & 1 & 5.82 & 5.00 \\
\hline 16 & 1 & 1 & 1 & 1 & 6.65 & 7.20 \\
\hline 17 & -2 & 0 & 0 & 0 & 1.76 & 4.60 \\
\hline 18 & 2 & 0 & 0 & 0 & 8.03 & 6.20 \\
\hline 19 & 0 & -2 & 0 & 0 & 9.83 & 10.60 \\
\hline 20 & 0 & 2 & 0 & 0 & 4.06 & 4.30 \\
\hline 21 & 0 & 0 & -2 & 0 & 10.10 & 10.66 \\
\hline 22 & 0 & 0 & 2 & 0 & 10.88 & 11.33 \\
\hline 23 & 0 & 0 & 0 & -2 & 8.63 & 9.20 \\
\hline 24 & 0 & 0 & 0 & 2 & 8.15 & 8.60 \\
\hline 25 & 0 & 0 & 0 & 0 & 11.54 & 11.33 \\
\hline 26 & 0 & 0 & 0 & 0 & 11.54 & 11.88 \\
\hline 27 & 0 & 0 & 0 & 0 & 11.54 & 11.70 \\
\hline 28 & 0 & 0 & 0 & 0 & 11.54 & 11.20 \\
\hline 29 & 0 & 0 & 0 & 0 & 11.54 & 11.50 \\
\hline 30 & 0 & 0 & 0 & 0 & 11.54 & 11.60 \\
\hline 31 & 0 & 0 & 0 & 0 & 11.54 & 11.60 \\
\hline
\end{tabular}


Table IV. Analysis of variance (ANOVA) for the experimental results of the central composite design (quadratic model).

\begin{tabular}{lrrrrr}
\hline Source $^{\mathrm{a}}$ & Sum of squares & $\mathrm{DF}^{\mathrm{b}}$ & Mean square & $F$ Value $^{2}$ & $p$ Value $^{\mathrm{c}}$ \\
\hline Model & 248.63 & 14 & 17.76 & 14.10 & $<0.0001$ \\
$X_{1}$ & 58.84 & 1 & 58.84 & 46.71 & $<0.0001$ \\
$X_{2}$ & 49.88 & 1 & 49.88 & 39.59 & $<0.0001$ \\
$X_{3}$ & 0.90 & 1 & 0.90 & 0.71 & 0.4112 \\
$X_{4}$ & 0.35 & 1 & 0.35 & 0.27 & 0.6076 \\
$X_{1} X_{2}$ & 18.84 & 1 & 18.84 & 14.95 & 0.0014 \\
$X_{1} X_{3}$ & 1.13 & 1 & 1.13 & 0.90 & 0.3568 \\
$X_{1} X_{4}$ & 1.80 & 1 & 1.80 & 1.43 & 0.2499 \\
$X_{2} X_{3}$ & 1.35 & 1 & 1.35 & 1.07 & 0.3167 \\
$X_{2} X_{4}$ & 1.07 & 1 & 1.07 & 0.85 & 0.3702 \\
$X_{3} X_{4}$ & 0.19 & 1 & 0.19 & 0.15 & 0.7002 \\
$X_{1}^{2}$ & 79.02 & 1 & 79.02 & 62.72 & $<0.0001$ \\
$X_{2}^{2}$ & 37.81 & 1 & 37.81 & 30.01 & 0.0001 \\
$X_{3}^{2}$ & 1.99 & 1 & 1.99 & 1.58 & 0.0017 \\
$X_{4}^{2}$ & 17.73 & 1 & 17.73 & 14.07 & \\
Residual & 20.16 & 16 & 1.26 & 38.47 & 0.0001 \\
Lack of fit & 19.85 & 10 & 1.98 & & \\
Pure error & 0.31 & 6 & 0.052 & & \\
Correlation total & 268.78 & 30 & & & \\
\hline
\end{tabular}

a $X_{1}$, glucose; $X_{2}$, yeast extract; $X_{3}, \mathrm{NH}_{4} \mathrm{NO}_{3} ; X_{4}, \mathrm{MgSO}_{4}$.

b Degree of freedom.

c $p<0.05$ are significant $R^{2}$ (predicted $)=0.9250 ; R^{2}$ (adjusted $)=0.8594$.

selected as the optimal $\mathrm{pH}$ value on the basis of the one-factor-at-a-time experiment. The concentration of $\mathrm{KH}_{2} \mathrm{PO}_{4}$ was fixed at $0.3 \mathrm{~g} / \mathrm{l}$.

Table II depicts the medium components selected and their concentrations. In order to investigate the combined effect of four different medium components (independent variables) on biomass and schizophyllan production, the fullfactorial CCD of $2^{4}=16$ plus 7 centre points and $2 \cdot 4=8$ star points leading to a total of 31 experiments was used for optimization of the components of the culture medium in submerged cultivation of $S$. commune.

Table III shows the CCD-predicted responses for schizophyllan production and the experimental results. The experimental values obtained from the CCD were regressed by a quadratic polynomial equation. Equation (3) represents the mathematical model relating the production of schizophyllan (yield) with independent process variables, $X_{i}$, and the second-order polynomial coefficient for each term of the equation determined through multiple regression analysis using the software Design Expert. The experimental and predicted values of yields of schizophyllan are also given in Table III. The coded values of independent variables are given in Table II.
The results were analysed using ANOVA (Table IV). ANOVA of the quadratic regression model and model $F$ value indicates the model to be significant. The model $F$ value is calculated as ratio of mean square regression and mean square residual. The model $p$ value (Prob $>F$ ) is very low (0.0001). This again signifies that the model is significant.

The $p$ value was used as a tool to check the significance of each of the coefficients, which are necessary to understand the pattern of mutual interactions between the test variables. The $t$ ratio and the corresponding $p$ values, along with the coefficient estimate, are given in Table IV. Trivial $p$ values (less than 0.05 ) indicate that the model parameters are significant. The coefficient estimates and the corresponding $p$ values suggest that, among the test variables used in the study, $X_{1}$ (glucose), $X_{2}$ (yeast extract), $X_{1} X_{2}$ (glucose-yeast extract), $X_{1}^{2}$ (glucose), $X_{2}^{2}$ (yeast extract), and $X_{4}^{2}\left(\mathrm{MgSO}_{4}\right)$ are significant model parameters with $p$ values less than 0.05 . Other parameters are insignificant. The coefficients of independent variables determined for the second-order polynomial model for the schizophyllan production are given as: 
yield $(\mathrm{g} / \mathrm{l})=11.54429+1.56583 X_{1}-1.44167$ $X_{2}+0.19333 X_{3}-0.12000 X_{4}-1.08500 X_{1} X_{2}+$ $0.26625 X_{1} X_{3}-0.33500 X_{1} X_{4}+0.29000 X_{2} X_{3}$ $-0.25875 X_{2} X_{4}-0.11000 X_{3} X_{4}-1.66232 X_{1}^{2}$ $-1.14982 X_{2}^{2}-0.26357 X_{3}^{2}-0.78732 X_{4}^{2}$. (3)

The fit of the model was also expressed by the coefficient of determination, $R^{2}$, which was found to be 0.9250 , indicating that $92.50 \%$ of the variability in the response could be explained by the model, suggesting that the predicted values exhibit a good correlation with experimental data and that the model is suitable and practicable.

Figs. $3 a-3 c$ present the three-dimensional response surfaces, which are the graphical representations of equation (3). Each plot shows the effect of two independent variables varying within the experimental range of schizophyllan production, while the other two variables were fixed at their respective centre point levels. Graphs are given here to highlight the roles played by significant factors. From the central point of the contour plot or from the bump of the 3D plot the optimal composition of medium components was identified. The optimal concentrations for the four components as obtained from the maximum point of the model were calculated to be $18 \mathrm{~g} / \mathrm{l}$ glucose, $0.5 \mathrm{~g} / \mathrm{l}$ yeast extract, $0.48 \mathrm{~g} / 1 \mathrm{NH}_{4} \mathrm{NO}_{3}$, and $0.05 \mathrm{~g} / \mathrm{l}$ $\mathrm{MgSO}_{4}$, respectively. The predicted maximum yield of schizophyllan was $11.74 \mathrm{~g} / 1$ under the optimum condition, which is in close agreement with the experimental value.

\section{Experimental validation of the optimized conditions}

In order to confirm the model accuracy and the results from the response surface analysis, three additional experiments were performed randomly with the optimal medium compositions. Table V shows the yields of schizophyllan before and after optimization. Significant difference $(p<0.05)$ is obtained. The results verify the previous model that glucose at $18 \mathrm{~g} / \mathrm{l}$, yeast extract at $0.5 \mathrm{~g} / \mathrm{l}$, $\mathrm{NH}_{4} \mathrm{NO}_{3}$ at $0.48 \mathrm{~g} / \mathrm{l}$, and $\mathrm{MgSO}_{4}$ at $0.05 \mathrm{~g} / \mathrm{l}$ are the best combination for obtaining the maximum schizophyllan production.

Fig. 3. Response surface curves of schizophyllan production by $S$. commune: the interaction between (a) glucose and yeast extract, (b) glucose and $\mathrm{NH}_{4} \mathrm{NO}_{3}$, and (c) glucose and $\mathrm{MgSO}_{4}$.
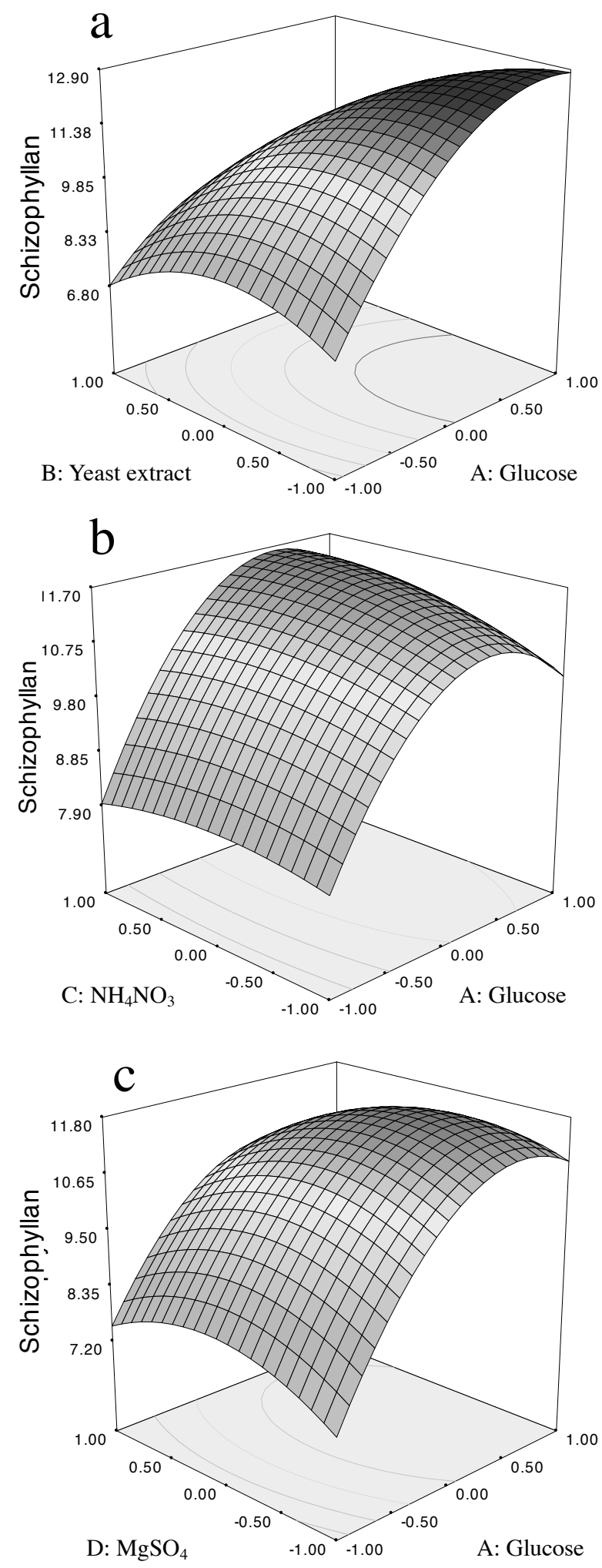
Table V. Optimized medium composition for schizophyllan production by S. commune.

\begin{tabular}{lccccc}
\hline $\begin{array}{l}\text { Serial } \\
\text { no. }\end{array}$ & Glucose & Yeast extract & $\mathrm{NH}_{4} \mathrm{NO}_{3}$ & $\mathrm{MgSO}_{4}$ & \multirow{2}{*}{ Schizophyllan $^{\mathrm{e}}[\mathrm{g} / \mathrm{l}]$} \\
\hline$y^{\mathrm{a}}$ & 12.0 & 1.0 & 0.0 & 0.1 & \\
$2^{\mathrm{b}}$ & 14.0 & 0.7 & 0.3 & 0.15 & $11.54 \pm 0.68$ \\
$3^{\mathrm{c}}$ & 18.0 & 0.5 & 0.48 & 0.05 & $12.65 \pm 0.75$ \\
$4^{\mathrm{d}}$ & 18.0 & 0.5 & 0.48 & 0.05 & $11.74 \pm 0.00$ \\
\hline
\end{tabular}

a The values before optimization.

b The composition of centre point.

c The optimized values derived from RSM regression and schizophyllan yield in this study.

d The predicted optimum values and predicted maximal schizophyllan yield derived from RSM regression in this study.

e Results are means $\pm \mathrm{SD}$ of three determinations with significant difference at $p<0.05$.

\section{Bioreactor fermentation results}

The feasibility of the regression model in a 5-1 scaled fermentor was also tested with the optimized medium. The maximum yield was $12.80 \mathrm{~g} / \mathrm{l}$ with a biomass concentration of $22.90 \mathrm{~g} / \mathrm{l}$ (DCW) after $7 \mathrm{~d}$ of cultivation.

Bolla K.-B., Shaheen S.-Z., Vasu K., and Singara Charya M.-A. (2008), Effect of oils on the production of exopolysaccharides and mycelial biomass in submerged culture of Schizophyllum commune. Afr. J. Microbiol. Res. 2, 349-352.

Chen W., Zhao Z., Chen S.-F., and Li Y.-Q. (2008), Optimization for the production of exopolysaccharide from Fomes fomentarius in submerged culture and its antitumor effect in vitro. Biores. Technol. 99, 3187-3194.

Cho E.-J., Oh J.-Y., Chang H.-Y., and Yun J.-W. (2006), Production of exopolysaccharides by submerged mycelial culture of a mushroom Tremella fuciformis. J. Biotechnol. 127, 129-140.

Hao L.-M., Xing X.-H., Li Z., Zhang J.-C., Sun J.-X., Jia S.-R., Qiao C.-S., and Wu T.-Y. (2010), Optimization of effect factors for mycelial growth and exopolysaccharide production by Schizophyllum commune. Appl. Biochem. Biotechnol. 160, 621-631.

Hobbs C. (1995), Medicinal Mushrooms: An Exploration of Tradition, Healing and Culture. Botanica Press, Santa Cruz, CA, USA, p. 251.

Hsieh C., Tsai M.-J., Hsu T.-H., Chang D.-M., and Lo C.-T. (2005), Medium optimization for polysaccharide production of Cordyceps sinensis. Appl. Biochem. Biotechnol. 120, 145-157.

Huang D., Cui F., Li Y., Zhang Z., Han X., Xiao X., Qian J., Wu Q., and Guan G. (2007), Nutritional requirements for the mycelial biomass and exopolymer production by Hericium erinaceus CZ-2. Food Technol. Biotechnol. 45, 389-395.
In conclusion, statistically based experimental designs proved to be effective tools to optimize the medium components for maximal schizophyllan production. It was possible to determine optimal medium components using RSM to maximize the production of schizophyllan by $S$. commune from an initial value of $9.57 \mathrm{~g} / \mathrm{l}$ to $12.80 \mathrm{~g} / \mathrm{l}$.

Kalil S.-J., Maugeri F., and Rodrigues M.-I. (2000), Response surface analysis and simulation as a tool for bioprocess design and optimization. Process Biochem. 35, 539-550.

Kim H.-O., Lim J.-M., Joo J.-H., Kim S.-W., Hwang H.J., Choi J.-W., and Yun J.-W. (2005), Optimization of submerged culture conditions for exopolysaccharides by Agrocybe cylindracea. Biores. Technol. 96, 1175-1182.

Kumari M., Survase S.-A., and Singhal R.-S. (2008), Production of schizophyllan using Schizophyllum commune NRCM. Biores. Technol. 99, 1036-1043.

Leathers T.-D., Nunnally M.-S., and Price N.-P. (2006), Co-production of schizophyllan and arabinoxylan from corn fiber. Biotechnol. Lett. 28, 623-626.

Lee B.-C., Bae J.-T., Pyo H.-B., Choe T.-B., Kim S.-W., Hwang J.-H., and Yun J.-W. (2004), Submerged culture conditions for the production of mycelial biomass and exopolysaccharides by the edible basidiomycete Grifola frondosa. Enzyme Microbial. Technol. 35, 369-376.

Luo J.-G., Liu J., Ke C., Qiao D., Ye H., Sun Y., and Zeng X.-X. (2009), Optimization of medium composition for the production of exopolysaccharides from Phellinus baumii Pilát in submerged culture and the immuno-stimulating activity of exopolysaccharides. Carbohydr. Polym. 78, 409-415.

Malinowska E., Krzyczkowski W., Lapienis G., and Herold F. (2009), Improved simultaneous production of mycelial biomass and polysaccharide by submerged culture of Hericium erinaceum: optimization using a 
central composite rotatable design (CCRD). J. Ind. Microbiol. Biotechnol. 36, 1513-1527.

Margaritis A. and Pace G.-W. (1985), Microbial polysaccharides. In: Advances in Biotechnology, Vol. 2 (Moo-Young M. and Robinson C.-W., eds.). Pergamon Press, Toronto, pp. 1005-1044.

Maziero R., Cavazzoni V., and Bononi V.-L. (1999), Screening of basidiomycetes for the production of exopolysaccharide and biomass in submerged culture. Rev. Microbiol. 30, 77-84.

Nour El-Dein M.-M., El-Fallal A.-A., El-Shahat A.-T., and Hereher F.-E. (2004), Exopolysaccharides production by Pleurotus pulmonarius: Factors affecting formation and their structures. Pak. J. Biol. Sci. 7, 1078-1084.

Rao J.-K., Chul-Ho K., and Sang-Ki R. (2000), Statistical optimization of medium for the production of recombinant hirudin from Saccharomyces cerevisiae using response surface methodology. Process Biochem. 35, 639-647.

Rau U. (1999), Production of schizophyllan. In: Methods in Biotechnology, Vol. 10. Carbohydrate Biotechnology Protocols (Bucke C., ed.). Humana Press, Totowa, NJ, USA, pp. 43-55.

Rau U. (2002), Schizophyllan. In: Biopolymers, Vol. 6. Polysaccharide II: Polysaccharide from Eukaryotes
(Vandamme E.-J., Baets S.-D., and Steinbuchel A., eds.). Wiley-VCH, Weinheim, pp. 61-91.

Rau U. and Brandt C. (1994), Oxygen controlled batch cultivation of Schizophyllum commune for enhanced production of branched $\beta$-1,3-glucans. Bioprocess Eng. 11, 161-165.

Shu C.-H. and Xu C.-J. (2007), Medium optimization for producing bioactive exopolysaccharides by Agaricus brasiliensis S. Wasser et al. $(=$ A. blazei Murrill ss. Heineim) in submerged culture. Food Technol. Biotechnol. 45, 327-333.

Survase S.-A., Saudagar P.-S., and Singhal R.-S. (2006), Production of scleroglucan by Sclerotium rolfsii MTCC 2156. Biores. Technol. 97, 989-993.

Tabata K., Ito W., Kojima T., Kawabata S., and Misaki A. (1981), Ultrasonic degradation of schizophyllan, an antitumor polysaccharide produced by Schizophyllum commune Fries. Carbohydr. Res. 89, 121-135.

Wagner F. (1988), Gewinnung mikrobieller Produkte für die Tertiärförderung von Erdöl. In: Angewandte Mikrobiologie der Kohlenwasserstoffe in Industrie und Umwelt (Schweisfurth R., ed.). Kontakt \& Studium Expert Verlag, Brandenburg Press, Berlin, pp. $65-83$. 